\title{
Нанопластинки $\boldsymbol{h}-\mathrm{WO}_{3}$ : синтез, микроморфология, характеризация
}

\author{
Троицкая И.Б., Гаврилова Т.А. \\ E-mail: troitskaia@thermo.isp.nsc.ru
}

Институт физики полупроводников им. А.В. Ржанова СО РАН, пр. Ак. Лаврентьева, 13, 630090, Новосибирск

\section{Nanoplates of $\boldsymbol{h}-\mathrm{WO}_{3}$ : synthesis, micromorphology, characterization}

\author{
Troitskaia I.B., Gavrilova T.A. \\ A.V. Rzhanov Institute of Semiconductor Physics, SB RAS, Lavrentieva Ave., 13, 630090, Novosibirsk
}

\begin{abstract}
Методом химического осаждения из водного раствора вольфрамата аммония азотной кислотой получены нанопластинки $h-\mathrm{WO}_{3}\left(P_{6} / \mathrm{mmm}, \mathrm{PDF} 33-1387\right)$ толщиной $\sim 10$ нм, диаметром до 200 нм светло-желтого цвета. Комплексом методов ДТА и РФА установлен $h$ - $\beta$ фазовый переход при $T=385^{\circ} \mathrm{C}$. Методами ИКи Раман-спектроскопии получены спектральные характеристики осажденной и прокаленной фаз.
\end{abstract}

Ключевые слова: нанопластинки; оксид вольфрама; вольфрамат аммония.

\section{1. Введение}

Современная тенденция миниатюризации электронных устройств поднимает проблему высоких требований к физико-химическим характеристикам используемых материалов [1]. В рамках решения этой проблемы интенсивно ведутся работы по разработке способов получения кристаллов с новыми сложными составами, установлению их функциональных характеристик [2-4], исследованию новых характеристик известных материалов, которые они проявляют в наноразмерном состоянии. Огромное значение для постановки данных исследований имеют работы, направленные на систематизацию физико-химических характеристик материалов $[5,6]$.

Оксиды переходных металлов, в частности оксиды вольфрама, широко используются в электронных приборах самого разнообразного назначения. Обладая выраженной анизотропией, оксиды вольфрама способны образовывать ряд полиморфных модификаций в зависимости от состава, температуры и давления. Каждая из фаз отличается специфическим набором физико-химических характеристик. Так, в зависимости от содержания кислорода, эти оксиды являются диэлектриками, полупроводниками и сверхпроводниками $[7,8]$. Полу-
Nanoplates of $\mathrm{h}-\mathrm{WO}_{3} \quad$ (P6/mmm, PDF 33-1387) with $\sim 10 \mathrm{~nm}$ thickness, up to $200 \mathrm{~nm}$ diameter and pale yellow color have been precipitated from aqua ammonium tungstate solution with nitric acid. The $\mathrm{h}-\beta$ phase transition at $\mathrm{T}=385^{\circ} \mathrm{C}$ has been established with DSC together with XRD. IR and Raman spectra are recorded both for precipitated and calcined phases.

Keywords: nanoplates; tungsten oxide; ammonium tungstate.

чение субмикронных и наноразмерных кристаллов разных полиморфных модификаций высшего оксида вольфрама с различной морфологией частиц представляет интерес вследствие увеличения удельной поверхности, доступности структурных туннелей и межслоевого пространства. Основными способами получения указанных форм, представленными в литературе, являются как высокотемпературные процессы окисления и возгонки, так и жидкостные: гидротермальный и метод химического осаждения из растворов. Высокотемпературным окислением металлической вольфрамовой фольги при $T=480^{\circ} \mathrm{C}$ на воздухе получены гексагональные наностержни $\mathrm{WO}_{2.92}$ (PDF 33-1387) диаметром от 40 до 200 нм, длиной до $15 \mu \mathrm{M}$ [9]. Проведение окисления в токе аргона и кислорода при $T=800 \div 1000^{\circ} \mathrm{C}$ привело к образованию наностержней триклинной модификации $\mathrm{WO}_{3}$

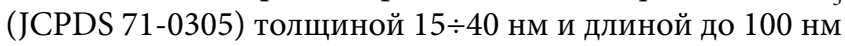
[10]. Гидротермальным способом из водного раствора вольфрамата аммония при $T=180^{\circ} \mathrm{C}$ осаждены сферические агрегаты $\mathrm{WO}_{3} \cdot 0.33 \mathrm{H}_{2} \mathrm{O}$ (JCPDS $35-0270$ ) размером до $3 \mu \mathrm{M}$, состоящие из наностержней диаметром 10 нм. Термообработка этих кристаллов при $T=350^{\circ} \mathrm{C}$ привела к превращению в гексагональную модификацию $h-\mathrm{WO}_{3}$ (JCPDS 33-1387) [11]. Гидротермальным способом при $T=200^{\circ} \mathrm{C}$ из водного раствора метавольфрамата аммония в присутствии азотной кислоты получены нано- 


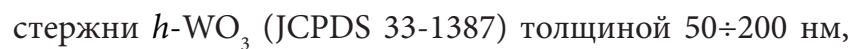
длиной до $3 \mu \mathrm{M}$ [12]. Осаждением из водного раствора паравольфрамата аммония азотной кислотой синтезированы округлые кристаллы $\mathrm{WO}_{3} \times \mathrm{H}_{2} \mathrm{O}$ (JCPDS 43-0679)

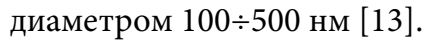

В настоящей работе представлен синтез моноразмерных нанопластинок оксида вольфрама в водном аммиачном растворе оксида вольфрама в присутствии азотной кислоты, отличающийся тем, что метастабильная гексагональная модификация указанного оксида получена непосредственным осаждением при $T=100^{\circ} \mathrm{C}$ без дополнительной термообработки материала. Представлены морфологические особенности кристаллов, изучена термическая стабильность осажденных кристаллов при прокалке до $T=500^{\circ} \mathrm{C}$ на воздухе.

\section{2. Экспериментальная часть}

Для постановки синтеза использовали оксид вольфрама $\mathrm{WO}_{3}$ «осч»; аммиак водный, «осч», концентрацией $C$ = 186,5 г/л; азотную кислоту, $\mathrm{HNO}_{3}$, «осч», $C=976$ г/л; дистиллированную воду. Синтез кристаллов $\mathrm{WO}_{3}$ осуществлялся в две стадии. Первая стадия (создание среды) заключалась в приготовлении водного аммиачного раствора оксида вольфрама. С этой целью 2,0 г исходного $\mathrm{WO}_{3}$ были растворены в 350 мл концентрированного водного раствора аммиака в термостойком стакане с покровным стеклом при непрерывном нагревании и перемешивании на магнитной мешалке в течение 3 часов. Полученный прозрачный бесцветный раствор имел значение $\mathrm{pH}=10$. На второй стадии (осаждение) к свежеприготовленному раствору с $T=100^{\circ} \mathrm{C}$ добавляли, не прекращая перемешивание, 30 мл концентрированной $\mathrm{HNO}_{3}$ до получения $\mathrm{pH}=1$ и выдерживали 30 минут. Осажденные кристаллы отделяли от маточного раствора центрифугированием, промывали дистиллированной водой до $\mathrm{pH}$ промывных вод $=6$, затем сушили на воздухе при комнатной температуре.

$\mathrm{pH}$ растворов контролировали иономером универсальным ЭВ 74. Фазовый состав образцов устанавливали методом рентгенофазового анализа (РФА) на рентгенов-

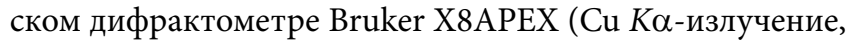
графитовый монохроматор, разрешение CCD-детектора $1024 \div 1024$ пикселей, расстояние до детектора $\mathrm{L}=50,1$ мм). Морфологию кристаллов исследовали методом растровой электронной микроскопии (РЭМ) на установке LEO 1430. Ускоряющее напряжение электронной пушки составляло 20 кВ. Дифференциальный термографический анализ (ДТА) проводили на приборе «PoulikPoulik» в потоке воздуха, в интервале температур $T=$ $20 \div 500^{\circ} \mathrm{C}$ со скоростью подъема температуры $V=10^{\circ} \mathrm{C}$ / мин. В качестве эталона применяли $\mathrm{Al}_{2} \mathrm{O}_{3}$. Инфракрасные (ИК) спектры получены с использованием спектрометра INFRALUM FT-801 (ОOО Люмэкс) при спектральном разрешении $1 \mathrm{~cm}^{-1}$ в диапазоне волновых чисел $v=500 \div 3600 \mathrm{~cm}^{-1}$. Образцы для измерения ИК спектров готовили методом запечатывания 1 мг исследуемого вещества в таблетку $\mathrm{KBr}$ массой 500 мг толщиной 1 мм. Спектры комбинационного рассеяния (КР) получены с использованием КР спектрометра RFS-100s (Brucker) при спектральном разрешении $1 \mathrm{~cm}^{-1}$ в диапазоне $v=0 \div 1000 \mathrm{~cm}^{-1}$.

\section{3. Результаты и обсуждения}

Представленный в настоящей работе синтез кристаллов $h-\mathrm{WO}_{3}$ осуществляли в две стадии. На первой стадии готовили стабильный раствор вольфрамата аммония, в котором атом вольфрама являлся анионообразователем, а образованный им вольфрамат-ион существовал в растворе в виде неассоциированного мономера $\left[\mathrm{WO}_{4}\right]^{2-}$. Данный раствор имел концентрацию вольфрама $C_{\mathrm{w}}=$ 0,0246 моль/л и $\mathrm{pH}=10$. На втором этапе синтеза добавлением концентрированной $\mathrm{HNO}_{3}$ достигалось резкое изменение $\mathrm{pH}$ маточного раствора и создание среды с низкой растворимостью оксида вольфрама, вследствие чего в течение 30 минут образовался светло-желтый осадок

Методом РЭМ установлено, что полученный осадок представляет собой округлые моноразмерные пластинки, показанные на Рис. 1. Как видно на рисунке, форма

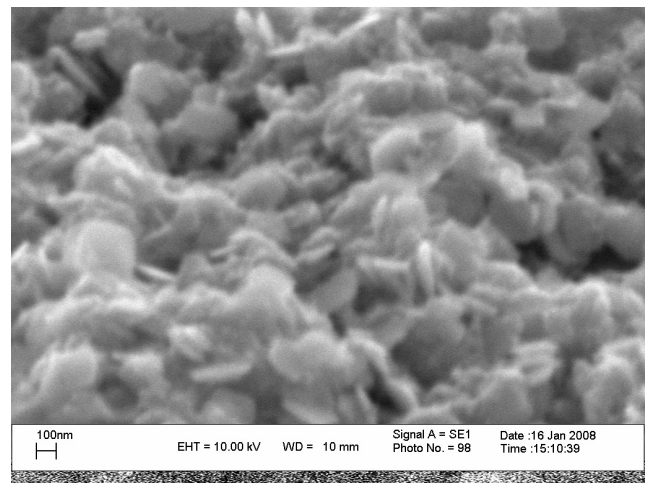

Рис. 1. РЭМ-изображение нанопластинок $\mathrm{WO}_{3}$.

пластинок близка к гексагональной, толщина их составляет 10 нм, диаметр - до 200 нм. Так же следует отметить, что их поверхность недостаточно плоская.

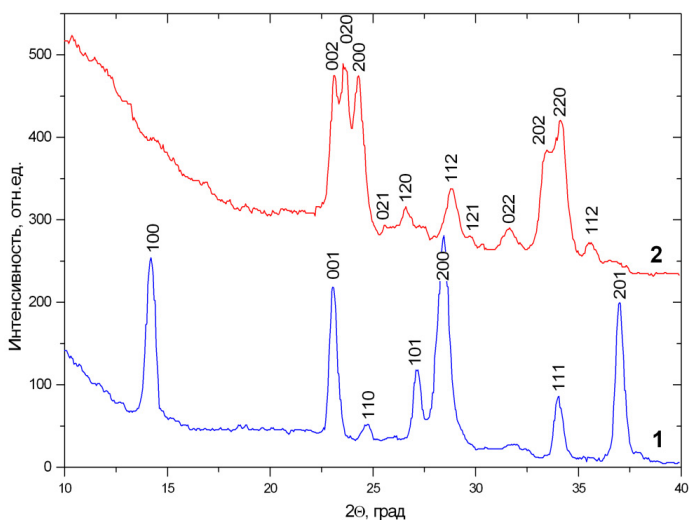

Рис. 2. Рентгенограммы кристаллов. Кривая 1 - для осажденных кристаллов. Кривая 2 - для кристаллов, прокаленных при $\mathrm{T}=500^{\circ} \mathrm{C}$.

Методом РФА установлено, что осажденные нанопластинки представляет собой кристаллы фазы $h$ - $\mathrm{WO}_{3}$ $\left(P_{6} / \mathrm{mmm}\right.$, PDF 33-1387). На Рис. 2 (линия 1) показана рентгенограмма данных нанокристаллов. Все наблюдаемые на рентгенограмме пики индексируются в рамках 
указанной фазы оксида вольфрама. Вместе с тем, на рентгенограмме в области углов $2 \Theta=10 \div 35$ градусов наблюдается аморфный фон.

Термическую стабильность нанопластинок $h-\mathrm{WO}_{3}$ при нагревании до $T=500^{\circ} \mathrm{C}$ в потоке воздуха исследовали методом ДТА. На Рис. 3 представлена термограмма, на которой показаны кривые DSC (дифференциальной сканирующей калориметрии), Т (изменения температуры образца) и TG (изменения массы образца).

Анализ термограммы показывает, что при подъеме температуры до $T=110^{\circ} \mathrm{C}$, на кривой TG наблюдается потеря 2\% массы образца, которая объясняется удалением влаги. При дальнейшем нагревании до $T=370^{\circ} \mathrm{C}$ образец теряет еще $12 \%$ массы, на кривой DSC при этом наблюдается продолжительный эндотермический эффект в области $T=110 \div 330^{\circ} \mathrm{C}$. В интервале $T=370 \div 385^{\circ} \mathrm{C}$

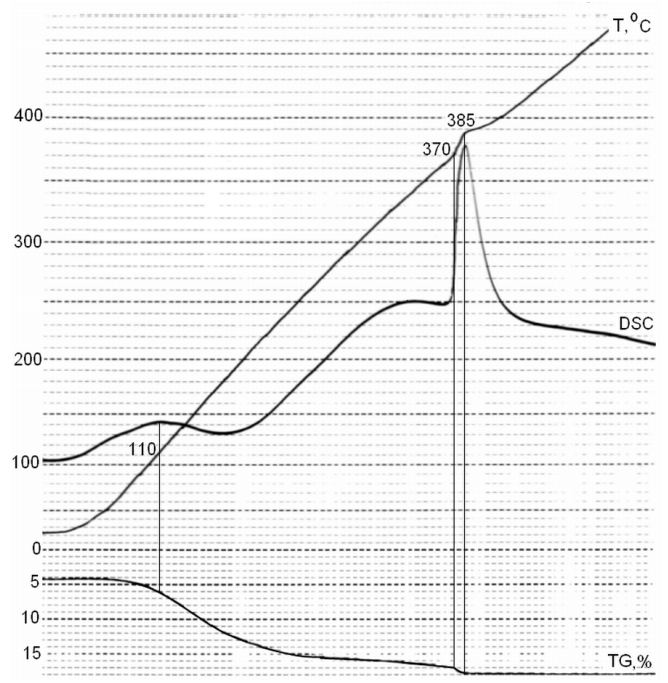

Рис. 3. Кривые ДТА для кристаллов $\mathrm{h}-\mathrm{WO}_{3}$

происходит резкая потеря $1 \%$ массы образца, которая сопровождается интенсивным пиком экзотермического эффекта на кривой DSC при $T=385^{\circ} \mathrm{C}$. При этой температуре наблюдается перегиб на кривой T, который свидетельствуют о том, что новая образованная фаза обладает меньшей теплоемкостью.

На основании расчетов потери массы, состав осажденных кристаллов довольно строго соответствует брутто-формуле $\mathrm{WO}_{3} \cdot 2 \mathrm{H}_{2} \mathrm{O}$. Однако столь большое содержание воды в составе кристаллов должно было вызвать значительное отклонение положений пиков на рентгенограмме от карточки PDF 33-1387 фазы $h$-WO, Поскольку такого отклонения не наблюдается, справедливо предположить, что вода адсорбирована поверхностью кристаллов. Это предположение объясняет так же и недостаточную плоскостность поверхности и наличие аморфного гало на рентгенограмме при точном соответствии положений пиков фазе $h-\mathrm{WO}_{3}$ (Рис. 2, линия 1)

Фазовый состав кристаллов, прокаленных при $T=500^{\circ} \mathrm{C}$ на воздухе, исследовали методом РФА, рентгенограмма показана на Рис. 2 (линия 2). Все пики на рентгенограмме индексируются в рамках моноклинной фазы $\beta-\mathrm{WO}_{3}\left(P 2_{1} / \mathrm{n}, \mathrm{PDF} 43-1035\right)$. Таким образом, при $T=385^{\circ} \mathrm{C}$ зафиксирован $h-\beta$ фазовый переход для нанопластинок оксида вольфрама. На представленной рентгенограмме, наряду с точным соответствием положений пиков указанной выше карточке, наблюдается аморфное гало в области углов $2 \Theta=10 \div 35$ градусов.

На основании анализа ИК спектров осажденной и прокаленной фаз, сделаны выводы об изменении состава кристаллов при прокалке. На Рис. 4 представлены ИК спектры, в Таблице 1 приведены численные значения частот полос поглощения, наблюдаемых для указанных образцов, и интерпретация полос, проведенная на основании литературных данных.

В области $v=500 \div 1000$ см-1 ИК спектра осажденных нанопластинок h-WO ${ }_{3}$ наблюдается интенсивная широкая полоса мостиковых колебаний O-W-O и характеристическая полоса при 960 см-1 внутренних W=O колебаний октаэдров [WO ]. Полосу при 1384 см-1 следует отнести к следам $\mathrm{NH}_{4}$, при прокалке она исчезает. Полоса при 1401 см-1 наблюдается на спектрах в работе [14]. Эта полоса при прокалке не исчезает, ее относят к колебательным модам центров Льюиса [15]. Далее при 1626, 3166,3443 см-1 (полосы при 3166 и 3443 см-1 на рисунке не показаны), лежат полосы поглощений групп ОН. Полоса при 3166 см-1 при прокалке исчезает.

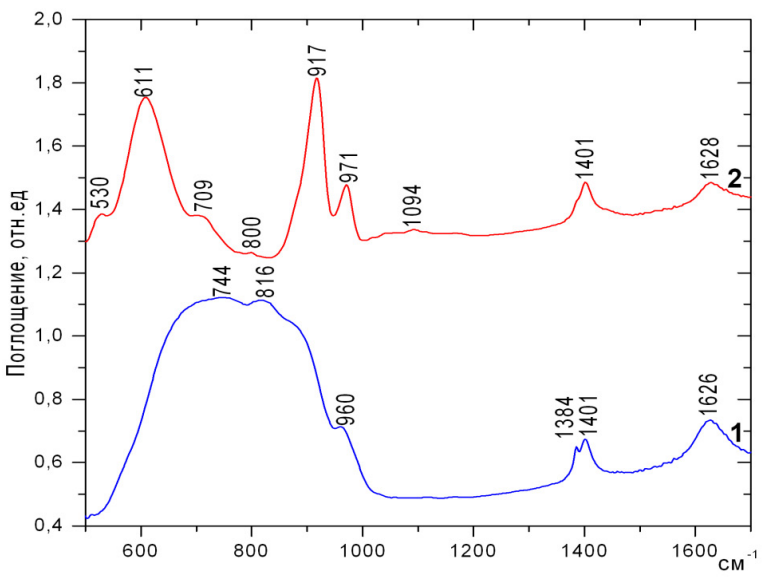

Рис. 4. ИК спектры. Кривая 1 - для осажденной h- $\mathrm{WO}_{3}$ фазы. Кривая 2 - для $\beta-\mathrm{WO}_{3}$ фазы, полученной прокаливанием осажденных $\mathrm{h}-\mathrm{WO}_{3}$ нанопластинок при $\mathrm{T}=500^{\circ} \mathrm{C}$ на воздухе.

ИК спектр фазы $\beta-\mathrm{WO}_{3}$, полученной прокаливанием осажденных нанопластинок, содержит интенсивную полосу в области $v=500 \div 709$ см-1, которую относят к структурным колебаниям W-O связей. Слабую полосу при 800 см-1 относят к мостиковым W-O-W колебаниям моноклинной модификации $\mathrm{WO}_{3}[16,17]$. Полосы поглощения при 917 и 971 см-1 относят к модам мостиковых O-W-O колебаний, при 1401 см-1 - к колебательным модам центров Льюиса. Полоса при 1628 см-1 после прокалки смещается и показывает меньшую интенсивность, что может быть вызвано удалением ОН-групп, адсорбированных поверхностью. Эту полосу справедливо отне-

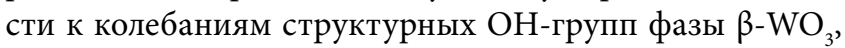
которые не удаляются прокалкой при $\mathrm{T}=500^{\circ} \mathrm{C}$, о чем свидетельствует плато после $\mathrm{T}=385^{\circ} \mathrm{C}$ на кривой $\mathrm{TG}$ термограммы (Рис. 3). К поглощениям структурных $\mathrm{OH}$ групп относится и полоса при 3443 см-1 (на рисунке не показана).

Таким образом, на основании приведенного анализа ИК спектров можно сделать следующие выводы:

- осажденные нанопластинки фазы $h$ - $\mathrm{WO}_{3}$ характеризуются развитой поверхностью с центрами Льюиса, 
которая способна активно адсорбировать воду и вносит аморфную составляющую, зафиксированную методом РФА (Рис. 2, кривая 1). Адсорбированная вода удаляется прокалкой до $T \approx 370^{\circ} \mathrm{C}$, что показывает кривая TG термограммы, показанная на Рис.3.

- кристаллы фазы $\beta$ - $\mathrm{WO}_{3}$ содержат в составе структурные группы ОН, которые не удаляются прокалкой при $T=500^{\circ} \mathrm{C}$.

На основании анализа КР спектров сделаны предположения о структурных особенностях нанопластинок $h-\mathrm{WO}_{3}$ и прокаленных кристаллов $\beta-\mathrm{WO}_{3}$. На Рис. 5 представлены КР спектры, измеренные для обсуждаемых образцов, в Таблице 2 приведены численные значения частот спектральных линий КР и их интерпретация, проведенная на основании литературных данных.

Рельеф КР спектра нанопластинок $h$ - $\mathrm{WO}_{3}$ (Рис. 5, кривая 1) довольно точно повторяет спектр нанокри-

Таблица 1. Положения и интерпретация полос поглощения в ИК спектрах для h- $\mathrm{WO}_{3}$ и $\beta-\mathrm{WO}_{3}$

\begin{tabular}{|c|c|c|c|}
\hline $\begin{array}{c}\text { Положение } \\
\text { полосы на } \\
\text { спектре } \\
h \text {-WO }, \mathrm{cm}^{-1}\end{array}$ & $\begin{array}{c}\text { Положение } \\
\text { полосы на } \\
\text { спектре } \\
\beta \text { - } \mathrm{WO}_{3}, \mathrm{~cm}^{-1}\end{array}$ & $\begin{array}{c}\text { Интерпретация полос } \\
\text { поглощения на осно- } \\
\text { вании литературных } \\
\text { данных }\end{array}$ & Лит \\
\hline & $\begin{array}{l}530 \\
611 \\
709\end{array}$ & Структурные W-O & $\begin{array}{l}{[15]} \\
{[16]} \\
{[18]}\end{array}$ \\
\hline \multirow[t]{2}{*}{714} & & Мостиковые O-W-O & [19] \\
\hline & 800 & $\mathrm{~W}-\mathrm{O}-\mathrm{W}$ & {$[16]$} \\
\hline \multirow[t]{2}{*}{816} & & Мостиковые O-W-O & [19] \\
\hline & 917 & Мостиковые O-W-O & {$[18]$} \\
\hline \multirow[t]{3}{*}{960} & & $\mathrm{~W}=\mathrm{O}$ октаэдров $\left[\mathrm{WO}_{6}\right]$ & [19] \\
\hline & 971 & Мостиковые O-W-O & {$[18]$} \\
\hline & 1094 & $\mathrm{~W}-\mathrm{O}$ октаэдров $\left[\mathrm{WO}_{6}\right]$ & $\begin{array}{l}14] \\
{[16]}\end{array}$ \\
\hline 1384 & & Следы $\mathrm{NH}_{4}^{+}$ & {$[20]$} \\
\hline 1401 & 1401 & $\begin{array}{ll}\text { Центры } & \text { кислот } \\
\text { Льюиса } & \\
\end{array}$ & {$[15]$} \\
\hline 1626 & 1628 & Группы ОН & {$[14]$} \\
\hline 3166 & & $\begin{array}{l}\text { W-OH, адсорбиро- } \\
\text { ванные поверхностью } \\
\text { кристаллов }\end{array}$ & $\begin{array}{l}{[14]} \\
{[15]}\end{array}$ \\
\hline 3443 & 3443 & Структурные ОН & {$[14]$} \\
\hline
\end{tabular}

сталлов $\mathrm{WO}_{3}$ размером 2 и 4 нм, полученных из раствора вольфрамата аммония, пропущенного через ионообменную смолу и прокаленного при $T=400^{\circ} \mathrm{C}$ [21]. Он так же похож на спектры фазы $h-\mathrm{WO}_{3}$, которые демонстрируют поглощения в области $v=100 \div 400 \mathrm{~cm}^{-1}$ и $v=600 \div 1000$ $\mathrm{cm}^{-1}$ [22-24]. При этом, в спектре полученном нами, отсутствуют линии при 270, 720 и $807 \mathrm{~cm}^{-1}$, характеристичные для кристаллических образцов данной фазы. Необходимо отметить, что в нашем спектре присутствуют линии при 119, 210, 221 см$^{-1}$, которые не наблюдаются в спектрах упомянутых работ [22-25]. Линия при 119 $\mathrm{CM}^{-1}$ показана в спектре округлых рыхлых наночастиц $\mathrm{WO}_{3}$ размером 30-50 нм в работе [26], авторы которой отнесли ее к колебаниям W-O. Линии в области 210 и $221 \mathrm{~cm}^{-1}$ присутствуют на спектрах частиц $\mathrm{WO}_{3}$, нанесен- ных на поверхность кристаллов $\mathrm{ZrO}_{2}$ [22], пленок $\mathrm{WO}_{3}$ [27] и округлых нанокристаллов $h$-WO диаметром до 50 нм [28]. Таким образом, спектральные линии при 119, 210 и 221 см $^{-1}$ встречаются в спектрах высокодисперсных оксидов вольфрама и, вероятно, вызваны колебаниями связей разупорядоченной поверхности кристаллов. Линию при $235 \mathrm{~cm}^{-1}$ относят к колебаниям мостикового кислорода связей $\mathrm{W}-\mathrm{O}-\mathrm{W}$, при $682 \mathrm{~cm}^{-1}$ - к внутренним

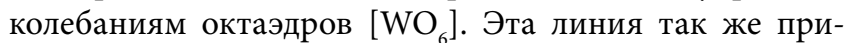
сутствует на спектре нанокристаллов $h$ - $\mathrm{WO}_{3}$ [28]. Интенсивную линию при $963 \mathrm{~cm}^{-1}$ относят к колебаниям $\mathrm{W}-\mathrm{OH}$ поверхности [21].

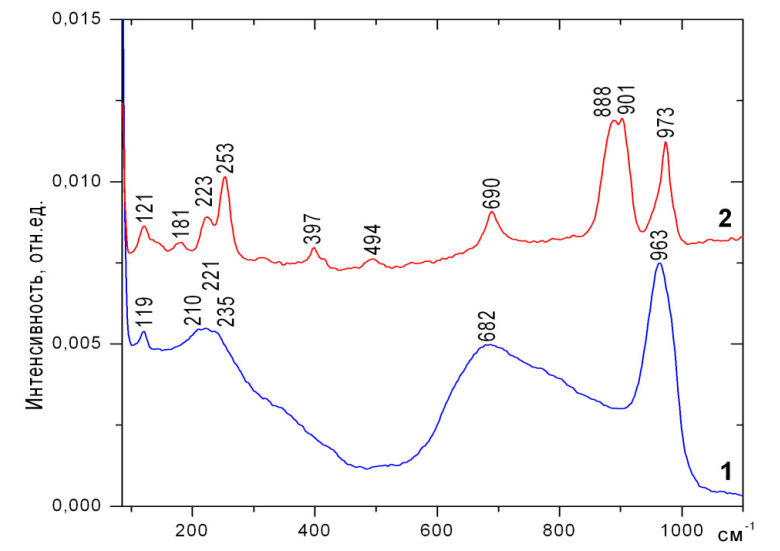

Рис. 5. КР спектры. Кривая 1 - для фазы h- $\mathrm{WO}_{3}$. Кривая 2 - для $\beta-\mathrm{WO}_{3}$ фазы.

Рельеф КР спектра кристаллов моноклинной фазы

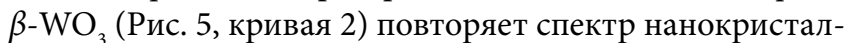
лов $\mathrm{WO}_{3}$ размером 35 нм, полученных из раствора вольфрамата аммония, пропущенного через ионообменную смолу и прокаленного при $T=600^{\circ} \mathrm{C}$ [21]. Спектральную линию при $121 \mathrm{~cm}^{-1}$ относят к колебаниям W-O. Линии при 181, 223 и 397 см$^{-1}$ присутствуют в спектре моноклинной модификации в работе [22, 25, 26, 28]. Линия при $253 \mathrm{~cm}^{-1}$ является характеристической для моноклинной модификации $\mathrm{WO}_{3}$. Спектральную линию при $494 \mathrm{~cm}^{-1}$ относят к колебаниям связи W-O-W. Интенсивные линии при 690, 880 и 901 см$^{-1}$ относят к внутренним колебаниям октаэдров [WO 6 ]. Интенсивную линию при $973 \mathrm{~cm}^{-1}$ относят к колебаниям связей $\mathrm{W}=\mathrm{O}$ в нанокристаллических структурах [10].

Таким образом, на основании анализа КР спектров обсуждаемых образцов, можно сделать следующие предположения об особенностях структуры обсуждаемых фаз:

осажденные нанопластинки $h$ - $\mathrm{WO}_{3}$ толщиной $\sim 10$ нм обладают необычной для данной модификации формой кристаллов, что выражается отсутствием характеристичных для объемных структур линий на КР спектре.

- поверхность осажденных нанопластинок характеризуется разупорядоченной структурой, вносящей аморфную составляющую в структуру кристаллов.

-прокалка нанопластинок $h-\mathrm{WO}_{3}$ при $T=500^{\circ} \mathrm{C}$ приводит к образованию моноклинной модификации $\beta-\mathrm{WO}_{3}$.

-поверхность полученных при прокалке кристаллов $\beta-\mathrm{WO}_{3}$, вследствие удаления адсорбированных групп $\mathrm{OH}$, характеризуется разупорядоченностью, которая 
вносит аморфную составляющую в структуру кристаллов.

\section{4. Заключение}

Предложенный метод позволяет синтезировать нанокристаллы $h-\mathrm{WO}_{3}$ с необычной для данной фазы формой в виде пластинок и развитой поверхностью, которая характеризуется наличием центров Льюиса и высоким содержанием адсорбированных групп ОН. Прокалка данных нанопластинок при $T=385^{\circ} \mathrm{C}$ приводит к удалению групп ОН с поверхности и фазовому превращению с образованием $\beta-\mathrm{WO}_{3}$, содержащей структурные группы ОН. Образованная фаза обладает наличием центров Льюиса и развитой разупорядоченной поверхностью. Установленные в настоящей работе особенности обеих фаз позволяют приступить к дальнейшему исследованию их функциональных свойств для применения в катализе, в качестве эффективных адсорбентов и компонентов композиционных составов.

Таблица 2.

Положения и интерпретация спектральных линий в КР спектрах для $\mathrm{h}-\mathrm{WO}_{3}$ и $\beta-\mathrm{WO}_{3}$

\begin{tabular}{|c|c|c|c|}
\hline $\begin{array}{l}\text { Положение } \\
\text { линии на } \\
\text { спектре } \\
h \text {-WO }{ }_{3}, \mathrm{~cm}^{-1}\end{array}$ & $\begin{array}{l}\text { Положение } \\
\text { линии на } \\
\text { спектре } \\
\beta \text {-WO }{ }_{3}, \mathrm{~cm}^{-1}\end{array}$ & $\begin{array}{c}\text { Интерпретация линий } \\
\text { на основании литера- } \\
\text { турных данных }\end{array}$ & Лит \\
\hline 119 & 121 & $\mathrm{~W}-\mathrm{O}$ & {$[26]$} \\
\hline $\begin{array}{l}210 \\
221\end{array}$ & $\begin{array}{l}181 \\
223\end{array}$ & $\begin{array}{l}\text { Поглощения струк- } \\
\text { турных фрагментов } \\
\text { разупорядоченной по- } \\
\text { верхности }\end{array}$ & $\begin{array}{l}\text { Наст. } \\
\text { иссл. }\end{array}$ \\
\hline \multirow[t]{4}{*}{235} & & $\begin{array}{l}\mathrm{W}-\mathrm{O}-\mathrm{W} \text { мостиковый } \\
\text { кислород }\end{array}$ & [24] \\
\hline & 253 & $\begin{array}{l}\mathrm{O}-\mathrm{W}-\mathrm{O} \text { моноклинной } \\
\text { структуры }\end{array}$ & $\begin{array}{l}{[29]} \\
{[30]} \\
{[26]}\end{array}$ \\
\hline & 397 & $\begin{array}{l}\text { Присутствует в спек- } \\
\text { тре моноклинной } \\
\text { фазы } \mathrm{WO}_{3}\end{array}$ & {$[26]$} \\
\hline & 494 & $\mathrm{~W}-\mathrm{O}-\mathrm{W}$ & {$[30]$} \\
\hline 682 & $\begin{array}{l}690 \\
880 \\
901 \\
\end{array}$ & $\begin{array}{l}\text { Внутренние колеба- } \\
\left.\text { ния [ } \mathrm{WO}_{6}\right]\end{array}$ & $\begin{array}{l}{[10]} \\
{[21]} \\
\end{array}$ \\
\hline \multirow[t]{2}{*}{963} & & W-OH поверхности & {$[21]$} \\
\hline & 973 & $\begin{array}{l}\text { Колебания связей } \\
\mathrm{W=O} \mathrm{в} \mathrm{нанокристал-} \\
\text { лических структурах }\end{array}$ & [10] \\
\hline
\end{tabular}

Авторы выражают благодарность в.н.с. ИНХ СО РАН, д.х.н. Васильевой И.Г. и заведующему Лабораторией оптических материалов и структур ИФП СО РАН, к.ф.-м.н. Атучину В.В. за обсуждение результатов и рекомендации.

\section{Литература}

1. A.A. Potapov. Nanotechnics. 17, 8 (2009). (in Russian)

2. R.M. Taziev. Fundamental Problems and Modern Technologies of Material Science. 5 (1), 90 (2008). (in Russian)
3. E. Bausk, R. Taziev, A. Lee. IEEE Trans. Ultrason., Ferroelect., Freq. Contr. 51 (8), 1002 (2004).

4. R.M. Taziev. IEEE Trans. Ultrason., Ferroelect., Freq. Contr. 57 (11), 2370 (2010).

5. B.I. Kidyarov, V.V. Atuchin. Fundamental Problems and Modern Technologies of Material Science. 7 (2), 26 (2010). (in Russian)

6. V.V. Atuchin, B.I. Kidyarov, N.V. Pervukhina. Fundamental Problems and Modern Technologies of Material Science. 4 (4), 91 (2007). (in Russian)

7. E.K.H. Salje. Eur. J. Solid State Inorg. Chem. 31, 651 (1994).

8. A. Aird, M.C. Domeneghetti, F. Mazzi, V. Tazzoli, E.K.H. Salje. J. Phys.: Condens. Matter. 10, L569 (1998).

9. Y. Xie, F.C. Cheong, B. Varghese, Y.W. Zhua, R. Mahendiran, C.H. Sow. Sens. Actuators B. 151, 320 (2011).

10. Y.-T. Hsieh, M.-W. Huang, C.-C. Chang, U.-S. Chen, H.C. Shih. Thin Solid Films. 519, 1668 (2010).

11. Z. Liu, M. Miyauchi, T. Yamazaki, Y. Shen. Sens. Actuators B. 140, 514 (2009).

12. R. Huirache-Acuña, F. Paraguay-Delgado, M.A. Albiter, J. Lara-Romero, R. Martínez-Sánchez. Mater. Charact. 60, 932 (2009).

13. S. Supothina, P. Seeharaj, S. Yoriya, M. Sriyudthsak. Ceramic. International. 33, 931 (2007).

14. C. Balázsi. Materials Structure. 6 (2), 135 (1999).

15. S. M. Kanan, Z. Lu, J.K. Cox, G. Bernhardt, C. P. Tripp. Langmuir. 18, 1707 (2002).

16. J. Pfeifer, C. Guifang, P. Tekula-Buxbaum, B.A. Kiss, M. Farkas-Jahnke, K. Vadasdi. J. Solid State Chem. 119, 90 (1995).

17. E. Brescacin, M. Basato, E. Tondello. Chem. Mater., 11, 314 (1999).

18. H.I.S. Nogueira, A.M.V. Cavaleiro, J. Rocha, T. Trindade, J.D. Pedrosa de Jesus. Mat. Res. Bull. 39, 683 (2004).

19. J. Polleux, N. Pinna, M. Antonietti, M. Niederberger, J. Am. Chem. Soc. 127, 15595 (2005).

20. N. Colthup, L. Daly, S. Wiberley. Introduction to Infrared and raman spectroscopy. New York and London. Academic Press. (1990) 547p.

21. M. Boulova, A. Gaskov, G. Lucazeau. Sens. Actuators B. 81, 99 (2001).

22. D.G. Barton, M. Shtein, R.D. Wilson, S.L. Soled, E. Iglesia. J. Phys. Chem. B. 103, 630 (1999).

23. H. Wang, X. Quan, Y. Zhang, S. Chen. Nanotechnology. 19, 065704 (2008).

24. S. Salmaoui, F. Sediri, N. Gharbi. Polyhedron. 29, 1771 (2010).

25. G.N. Kustova, Yu.A. Chesalov, L.M. Plyasova, I.Yu. Molina, A.I. Nizovskii. Vibrat. Spect. 55, 235 (2011).

26. Z. Lu, S.M. Kanana, C.P. Tripp. J. Mater. Chem., 12, 983 (2002).

27. Y.S. Kim. Sens. Actuators B. 137, 297 (2009).

28. I.M. Szilágyi, S. Saukko, J. Mizsei, A. L. Tóth, J. Madarász, G. Pokol. Solid State Sci. 12, 1857 (2010).

29. X.-L. Li, J.-F. Liu, Y.-D. Li. Inorg. Chem. 42 (3), 921 (2003).

30. M. Boukriba, F. Sediri, N. Gharbi. Polyhedron. 29, 2070 (2010). 